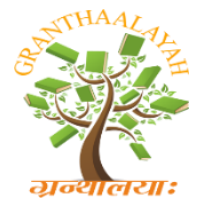

\author{
INTERNATIONAL JOURNAL OF RE
GRANTHAALAYAH \\ A knowledge Repository
}

Arts

\title{
SOME REPESENTATIVE FOLK ART OF INDIA
}

\author{
Dr Anjali Pandey *1 \\ ${ }^{* 1}$ Assistance Professor H.O.D. Drawing \& Painting Department Government M.L.B. Girls P.G. \\ Autonomous College Bhopal, India
}

\begin{abstract}
Indian folk art has its own recognition in universal context. It transmits from generation to generation having their own experience. Religious ceremonies and ritual acts are necessary for achieving psychological refinement. The folk culture moves around the elements of nature. The shapes are often symbolic and come out from their observations in simple pictorial language. The ritual paintings are generally created on wall, paper, cloth, and floor. The figures of human beings, animal, along with the daily life scene, mythological and rituals are created in rhythmic pattern with regional essence. Folk peoples express themselves in vivid styles through the paintings, this was the only means of transmission and inculcation of the culture through folk lore to a populace those who are not familiar with the written word. The traditions of folk culture are surviving in Odissa, Bengal, Andhra Pradesh, Maharashtra and Kerala are the unique representation of the region. Yet the changes with the time are noticed but characteristically folk art is not influenced by the time of change in academic or fine art circles and movements of Era.
\end{abstract}

Keywords: Pattachitra; Rituals; Mythological; Mother Nature; Geometrical Forms; Traditions; Lord Jagannath; Scroll Paintings; Kalams; Floor Picture; Devi; Nag; Kalamkari; Textile; Block Prints; Warli; Wall Painting.

Cite This Article: Dr Anjali Pandey. (2020). "SOME REPESENTATIVE FOLK ART OF INDIA." International Journal of Research - Granthaalayah, 8(3), 348-356. https://doi.org/10.29121/granthaalayah.v8.i3.2020.169.

\section{Introduction}

"Although Indian art tradition is a topic which many distinguished men have gone over with great scholarship and eloquence most Indian artists feel a need, just the same, to do it fresh. For they have, sooner or later, to come to terms with the environment and in any civilized society its history is large part of this environment, specially in a country like India where communities in thought, art and literature have persisted unbroken for two thousand years"1

The Indian folk artist have everlasting regional and traditional themes on rituals, social and moral values. The depiction of victory on evil, existence and demise, virtuous and wicked, are some of them.Chansonniars in India are dessiminating the values through folk lore, verses and 
songs.Paintings and scroll potrays themes based on Socio-cultural senario and human values with the adoption and transmition of tradition kept them alive since long. ${ }^{2}$

The research traces that Folk Art is characterized by a native style, this is the art of people who are exposed to changing landscapes as they travel over the valleys and highlands of India. The records of folk artists ideas, images and impressions seem to be inspired by nature, in which traditional rules of proportion and perspective are not employed. ${ }^{3}$ They learn traditional skills and techniques through discipleships in informal community settings, though they may also be formally educated. The folk spirit has a tremendous role to play in the development of art and in the overall consciousness of indigenous cultures. ${ }^{4}$

Folk arts are simple, ethnic, apparent, and mostly colourful. The nature of folk art is specific to its particular culture. Primarily it is utilitarian and decorative rather than purely aesthetic if traditional materials are impassable, new materials are often substituted, resulting in contemporary expressions of traditional folk art forms. ${ }^{5}$ It encircles a range of utilitarian and decorative media, including cloth, wood, paper, clay, metal and more. It reflects traditional art forms of diverse community groups - ethnic, tribal, religious, occupational, geographical, and age- or genderbased - that identify with each other and society at large. ${ }^{6}$

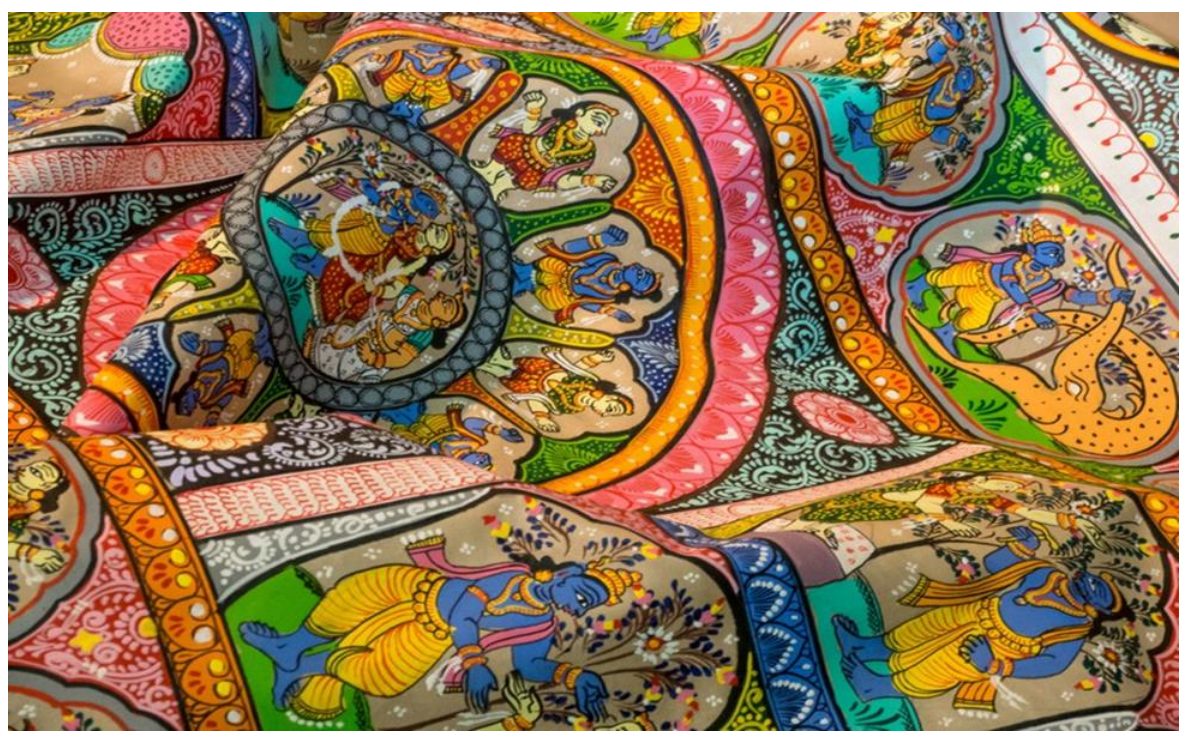

\section{Folk Arts of India - A Case Study}

"India had always been known as the land that portrayed cultural and traditional vibrancy through its conventional arts and crafts." 7

Different styles of arts enhance from ancient time have passed down from generation to generation. ${ }^{8}$ The extent of ceremonial drawing consequently grow as per the subject matter. ${ }^{9}$ The forms and motifs, colours and patterns speaks about the rich heritage of every region of India. Some of most famous folk of India are Pattchitra- The scroll painting of Odisha and Bengal, Kalamkari- The block printed or hand painted textile of Andhra Pradesh and Telangana, Kalamezhuthu- The ritual floor art of Kerala, Warli - The wall painting of Maharashtra. 


\section{Pattchitra}

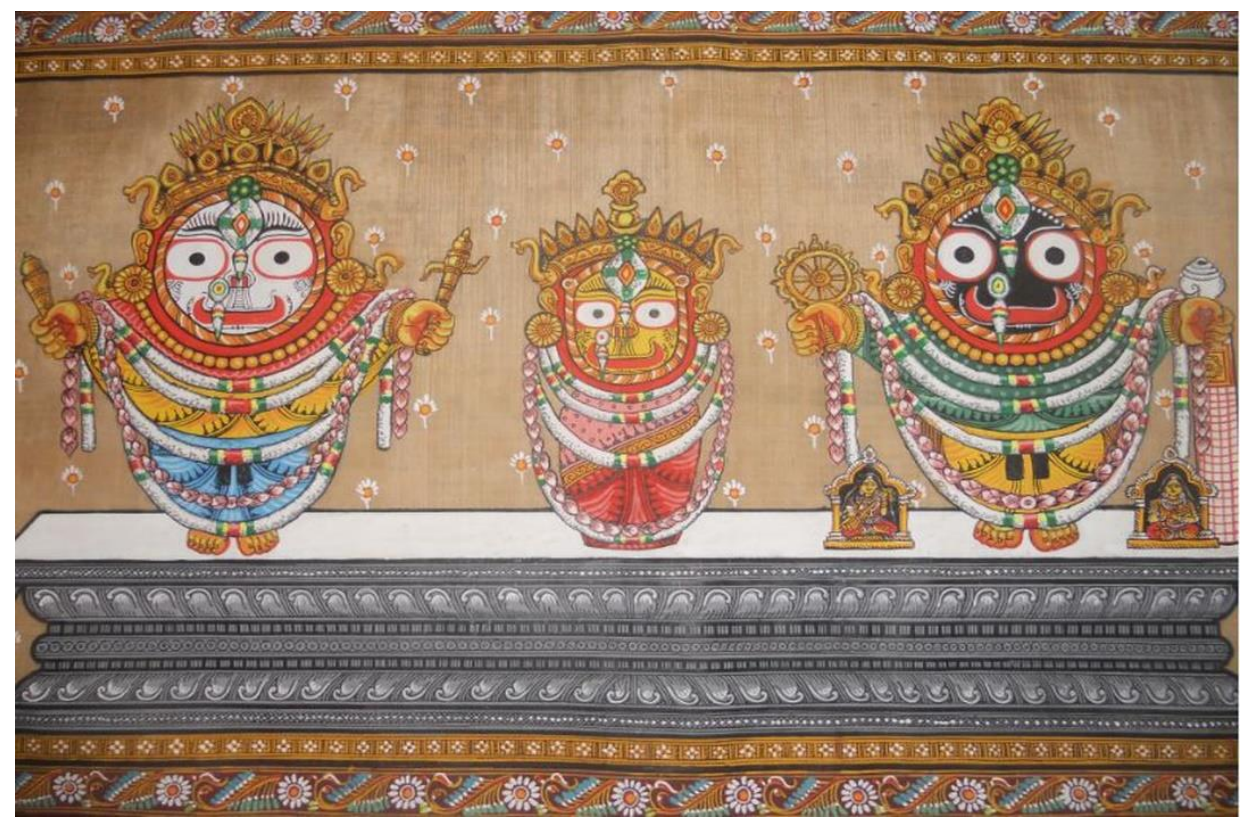

\section{Pattchitra}

Pattchitra is the oldest art form of Orissa originated as early in $12^{\text {th }}$ century. The word pattachitra derived from the Sanskrit word Patt means cloth and chitra means painting. ${ }^{10}$ It is the most popular living art of India. The art related to Lord Jagannath and tradition of Puri temple cult. The paintings narrate the intricate details on the mythologies, stories, and beliefs of Vaishnav cult on the scroll. Craftsmen apply the natural colours in paintings. ${ }^{11}$

The Canvas cloth is prepared for the painting by the coating of white stone powder and gum made of tamarind seeds. Kaitha tree's gum is used for making the base coating. ${ }^{12}$ Patachitra folk paintings are also drawn on paper and wall. These types of paintings are also found in Rajasthan Madhubani and North Bihar. The regions of Orissa, Bengal and Assam have the specific type of paintings that are called scroll paintings. Scroll paintings have continuous illustrative representation based on mythological themes. ${ }^{13}$

The paintings have the main focus on the figures and their actions. The faces are profile with elongated eyes. ${ }^{14}$ The background of the painting is represented in a simple and symbolic manner. ${ }^{15}$ The lines are bold and instinctive. The artists are so expertise in their work that they do not draw the primary line drawings, they directly draw them with the brush strokes in light red or yellow colour. Bright colours like yellow red Indigo black and white are used to fill the figures. ${ }^{16}$ Features of each character are defined with dark lines. The landscape scene of the forest is narrated by the depiction of the few trees. Paisley, flower and leaf are used for aesthetic application in artwork. The features of the scroll paintings are similar to the mural painting. Decorative borders are given for uniformity of the painting. The paintings are created in the form of design. ${ }^{17}$

The themes of the scroll paintings of Odisha stands near the Vaishnav cult. The mythological religious stories of Lord Jagannath, Balbhadra and Subhadra Radha Krishna, Ragchitra, Ramayan, 
Mahabharat, Shaiv and Shakta paintings and Geet Govinda of Jaidev are the main source of inspiration for pattuas. ${ }^{18}$

Patt artists are also known as chitrkar. All the family members of the patt chitrkar are engaged in preparation of patachitra. The mixture of chalk and gum of tamarind seeds is used for coating the cloth when the court get dry the surface is rubbed smooth to make them ready for the painting. The colours and dyes are natural, which they prepared from Minerals and vegetables. Black colour is made from Burning of coconut shells and white is prepared from the powder of conch shells, haritala stone is used to make yellow and hingula is used for red. Brushes are made by the bamboo stick and the hairs of domestic animals by tying the bunch of hairs at the end of the bamboo stick. ${ }^{19}$ After completion of the painting the lacquer coating is applied on the surface of Canvas.

The patuas of Bengal applies tremendous colour scheme in their painting based on mythological themes and on the subject of current affairs as they delivered. Beside the rectangular and scroll pat, Sara-Patt and Ghata-Patt is also prepared. Sara-Patt or Durga patt is used for the worship of goddess Durga. Ghat or pitcher symbolises the Treasure and prosperity. ${ }^{20}$ The colour scheme used to apply a natural Red Green Brown yellow blue white and black are used in paintings. ${ }^{21}$

Kalighat pattachitra are the last tradition of Bengal pattchitra paintings. Jamini Roy the famous artist of Bengal school developed this tradition. ${ }^{22}$ Patuas of Kalighat are tremendously efficient in their line drawings, caricature and satirical drawings ${ }^{23}$. The black and white paintings are best examples of their work. Kalighat paintings are best innovative representatives of the time.

\section{Kalamkari}

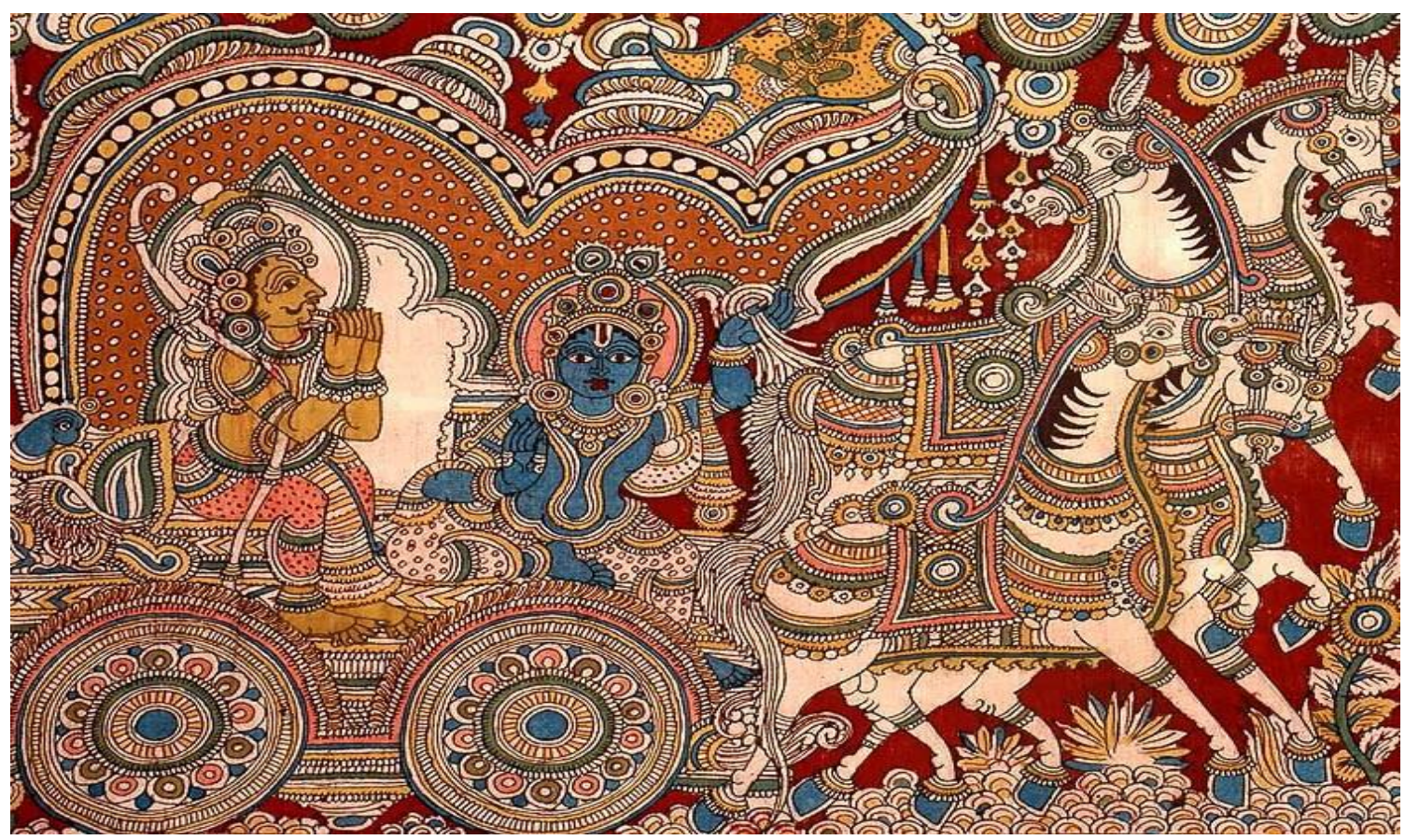

The traditional art of Kalamkari of Andhra Pradesh and Telangana are the finest example of ancient regional art. 
The word Kalamkari is originated from the Persian word 'Kalam' which denotes pen and 'kari' means craftsmanship, which flourished under the patronage of Golkonda Sultanat. ${ }^{24}$ It is a hand painting or block printed style done on the cotton or Silk textile. The most important aspect of painting is that the art involved in 23 steps by natural colours. Depiction of Hindu mythological stories based on Hindu Epic - Ramayana, Mahabharat, Puran tells the belief and ideologies of the regional art. ${ }^{25}$

Natural dyes and colours are used; all of which are made from fruits and vegetables and earthen colours like green, rust, mustard yellow, Indigo and black. The colours used in Kalamkari are bright and vibrant. Chitrakar used the tamarind pen or kalam to sketch the motifs and figures of flora and fauna. It is a complete free hand painting style. The applications of the outline drawing and filling both are freehand.

Kalamkari is an art which is originated from storytelling art. This was illustrated on the large piece of canvas. In ancient time people or guild of Chitrakar, who travel from one place to another told the stories on mythological themes. They generally recited the popular stories of epics, at that time they use the illustrated pictures related to the matter of the story thus the art play the important role for religion when the artist choose the mythological subject for narration he seems to be aware of the religious context and regional style. ${ }^{26}$

This art flourished around the temple that's why banners of the temple scroll, Temple hangings depicted the images of God and Goddesses like Lord Ganesh, Bhagwan Jagannath, Vishnu, Krishna, Devi Parvati and others. The scenes are taken from the Hindu epics and mythology. ${ }^{27}$ They generally recited the popular stories of epics, at that time they use the illustrated pictures related to the matter of the story thus the art play the important role for religion when the artist choose the mythological subject for narration he seems to be aware of the religious context and regional style.

The Kalamkari art has two distinguished style the Machilipatnam style and the Shrikalahasti style. The Shrikalahasti style of art is still continuing the Kalamkari or pen drawing. It is a complete free hand painting style. The applications of outline drawing, filling both are free hand. ${ }^{28}$ The borders of the painting have decorated with floral motifs. Bamboo or date Palm stick with pointed edge dipped in the mixture of fermented jaggery and water is used as a Kalam, to create the outline of design. The cloth is soaked in resin and cow milk to get characteristic Shine. To get the characteristic shine the Alum is used for stability of colours. The use of cow dung, seeds powder of crushed flower and different plants is used to achieve the different effects of colour on the fabric. Now these days the modern designs are come up with the recent applications on silk, cotton, Malmal and synthetic fabric. ${ }^{29}$ The Kalamkari designs depicted on saree, dupattas and blouse pieces with elegant choice are popular in Indian market. In Machilipatnam the block printing textile with hand carved block are produced. The Kalamkari prints are accepted by the people of all generations. It is also used for Furnishing materials. ${ }^{30}$ 


\section{Kalamezuthu}

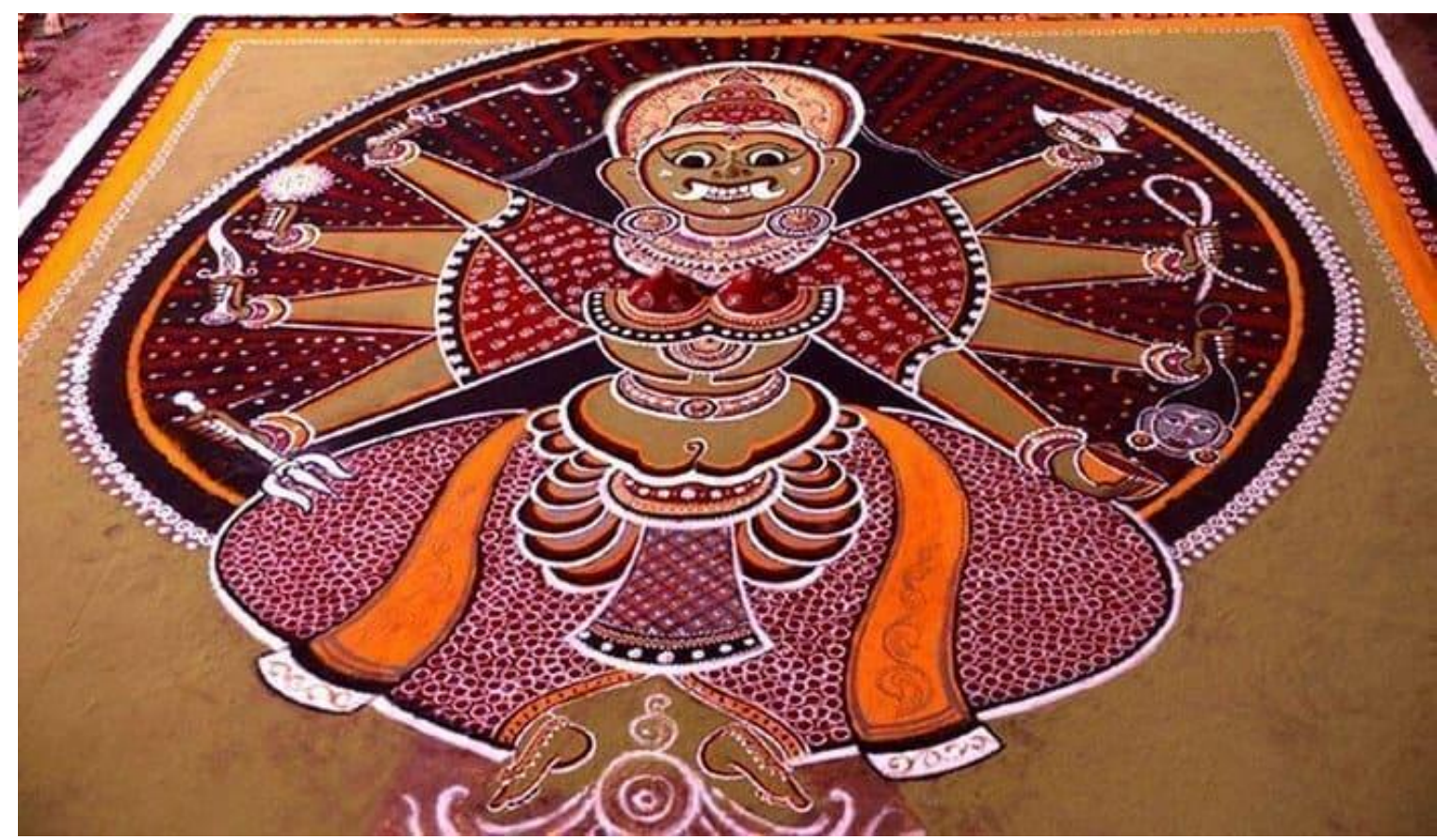

Kalamezuthu is the temple art usually conducted as a part of ceremonies and rituals. Kalams are drawn with affinity in the worship of Devi, Nag and Sastha. ${ }^{31}$ Figures are based on the regional rituals such as Bhadrakali, Gulikan, Yakshini, Gandharv, and Sarpam etc. The art Kalamezhuthu performed at Bhadrakali Temple is known as Bhadrakali Kalam. ${ }^{32}$

The Pulluvar Society of Kerala worship Nag or serpents as they are presumed as a God of Earth. Naga Kalam and Pulluvan pattu are significant rituals of pulluvar guild performed to appease the Nagraj for happiness and peace.

People of Vannan society performs the rituals singing and drawing the Kalam art is performed in pandal which is specially built for the rituals. The figures of Raktheshwari, Gandharv, Bhairav, KaruKalaki and other Goddesses are drawn. ${ }^{33}$

Kalams are drawn directly with hands. The artist creates the very large pictures on the floor. Coloured powder in five natural colours viz white, black, green, red and yellow are used for creating the Kalam. White colour is made from the extract of rice flour, black from charcoal, green from leaves turmeric is used for yellow and the mixture of lime and turmeric is used for red colour. ${ }^{34}$ The oil lamps are used for lightening, hymens are sung in praise of deity being worshipped. ${ }^{35}$

The art with its uniqueness has the big spectrum of fine art since the age of Sangham age. The festival Kalamehzuthu is organized by Lalit Kala Akademy for the existence and promotion of ancient unique art. ${ }^{36}$ 


\section{Warli Painting}

Warli is the traditional tribal folk-art style of Maharashtra mainly done by the women folk artist. The tribal people of north Sahyadri range have great respect to Nature as a mother and wildlife. The ancient artists use the walls as a canvas to execute their expressions in forms of human being and animals.

In $1770 \quad 37$ it was retraced and recognized. The styles of the figures stand near the prehistoric paintings. Themes of the painting are hunting, dancing, farming, ${ }^{38}$ fishing, and day to day life activities.

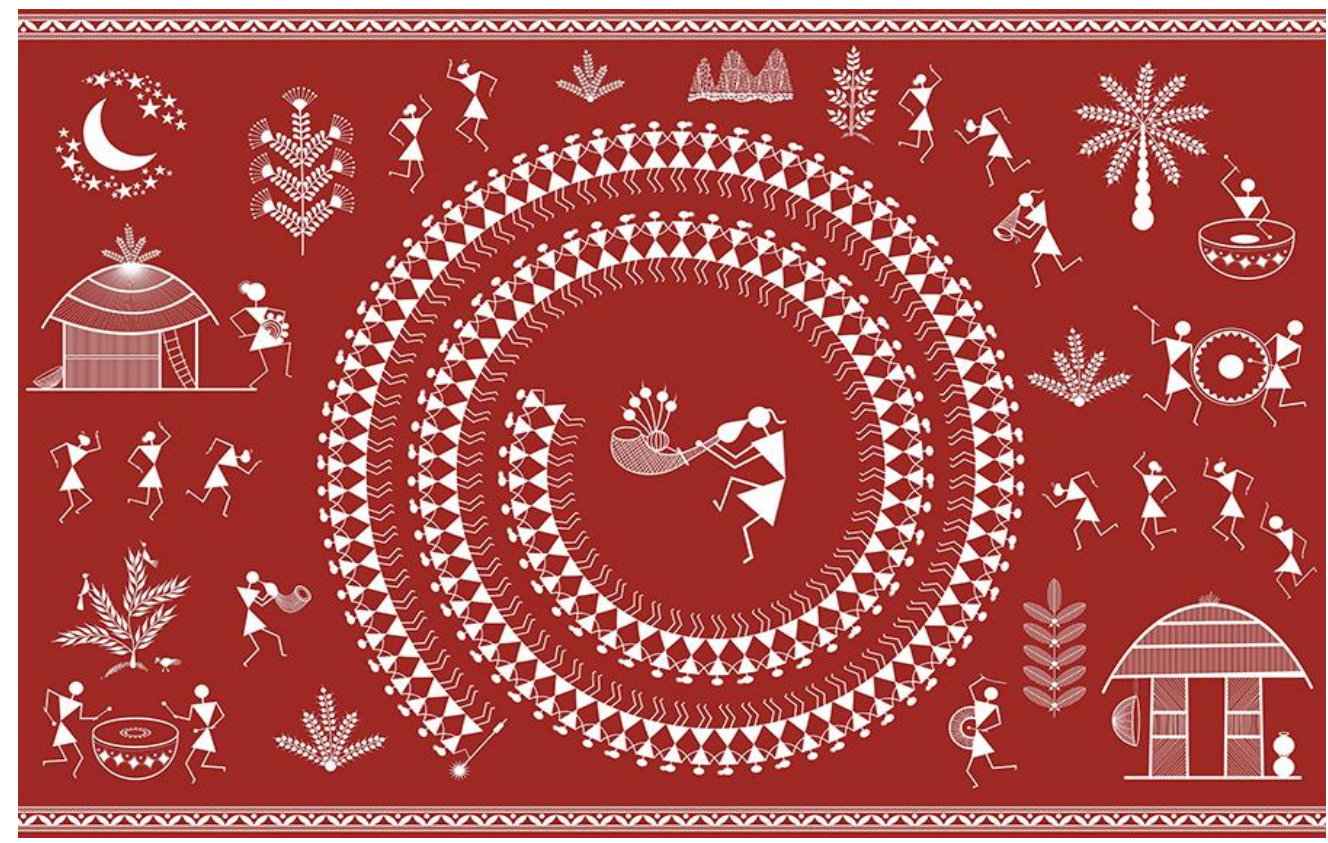

Figures are depicted in geometrical and symbolic forms. People and animals in the painting are depicted by 2 inverse Triangle joints at the points. The upper portion of the man figure has big Triangle rather than the female figure. The lower portion of the female figure has denoted by triangle.

The Warli are painted only in white colour made from rice paste with water and gum is used to buy the pigment. Generally, artists express their art on mud walls, with white colour they usually depict the human figures engaged in their activities, trees and huts are made as surroundings. The paintings do not depict the mythological themes and characters. Walls are made of mixture of fodder red brick and mud. Bamboo stick is used as a paint brush. On special occasions like wedding and rituals they used paint their walls. Now these days the art adopted some contemporary materials like paper and Canvas. Walls are the painted not only on occasions and ritual, but they started to paint as an artistic activity. ${ }^{39}$

"Tradition is not only a worn-out topic; its reading will differ from individual to individual, certainly from generation to generation; and it calls for fresh exposition from time to time". ${ }^{40}$ 


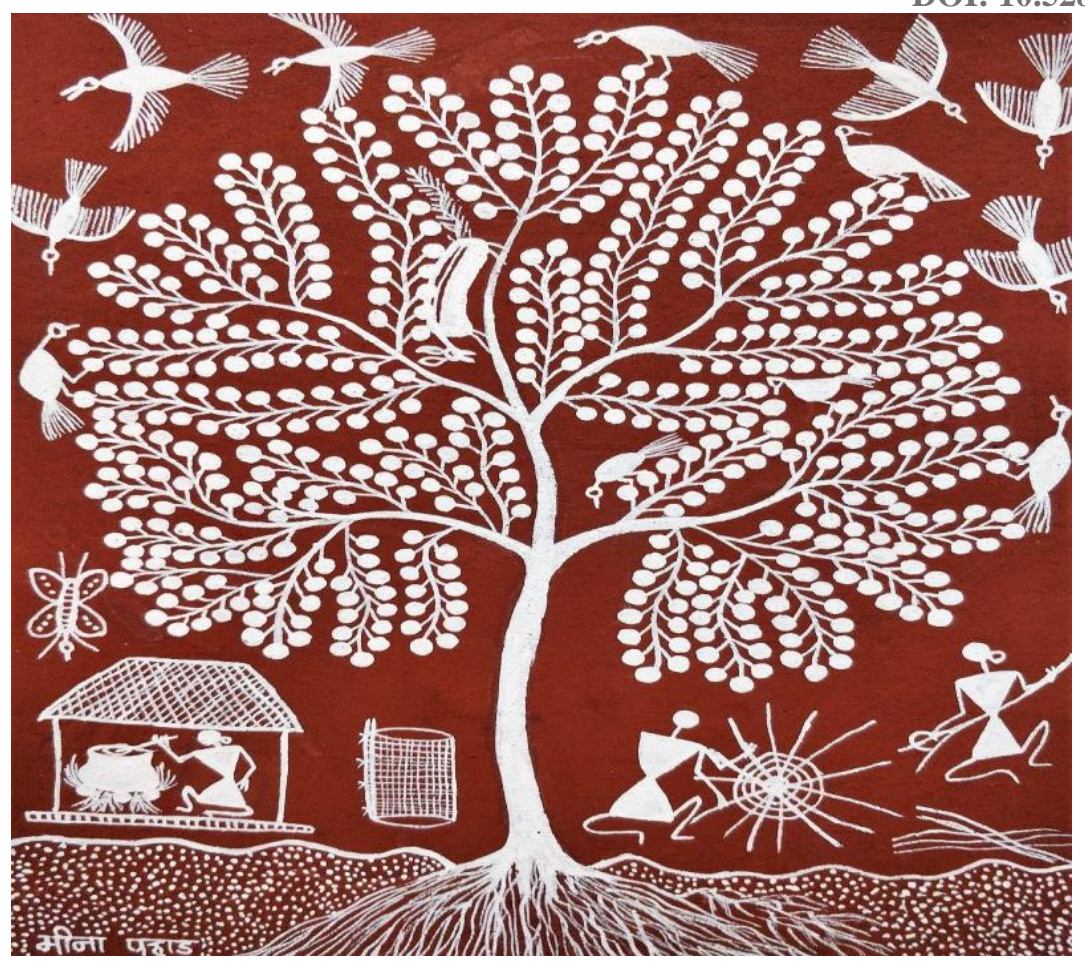

"It is a happy sign of the present age that serious thinkers and mature minds of the west are now realising the need of grafting the best elements of Indian culture on the tree of Western civilization" 41

\section{Conclusion}

India is a land of the native styles of paintings and folk art that portrayed the cultural, traditional vibrancy, each of which has a rich historical perspective. The varied geographical and temporal prevalence and diversity of folk art make it difficult to describe as a whole. The varied geographical and temporal prevalence and diversity of folk art make it difficult to describe as a whole, though some patterns have been demonstrated. The eternal presence of the cosmos on the Indian art remains associated through centuries. Various moods, seasons and the traditions execute the maintained relationship of the human in specific style and technique. ${ }^{42}$ The nature of folk art is specific to its particular culture .20th Century technological empowerments lead to a notable change in Indian popular taste causing a temporary decline to Indian folk art and culture. As a phenomenon that consecutively move towards civilization yet rapidly diminishes with modernity, industrialization, or outside influence. The mainstream academic style of art synergized with the principle of vernacular folk and tribal is to boost nationalism and modernism in Indian art scene. "Yet the deep-rooted tradition of Indian art has its existence and identity since long and interpreting the extract of Indian culture from generation to generation" 43

\section{References}

[1] Subramanian K.G.: Moving Focus, Lalit Kala Academy, New Delhi, 1978. Page 89

[2] Mookerji Ajit: Folk art of India, Clarion books, New Delhi, 1986,page 63- 65

[3] Ibid : page 14-20 
[4] Mukherjee Radhakamal: Social Function of Art, Bhartiya Vidya Prakashan, Delhi, Varanasi 1988, page - 30- 50

[5] Kaushik Dinkar: Kal Aur Kala, Rajhans Prakashan, Delhi- 6, Patna- 6, 1967, page 86- 88

[6] Thakurta Roy, Shatarupa; Aesthetic continuum of contemporary folk paintings of india:case study of five traditional practices /http://gyan.iitg.ernet.in/handle/123456789/568)

[7] www.indianfolkarts.com

[8] Mukherjee Radhakamal: Ibid page 226

[9] Mukherjee Radhakamal:Ibid page 63-65

[10] https://theculturetrip.com/asia/india/articles/pattachitra-a-spectacular-folk-art-form-from-odisha

[11] https://www.utsavpedia.com/motifs-embroideries/pattachitra-on-clothing

[12] Culture trip Ibid

[13] Mookerji Ajit: Ibid, page

[14] Culture trip Ibid

[15] https://www.utsavpedia.com/motifs-embroideries/pattachitra-on-clothing

[16] https://en.ikipedia.org/wiki/pattachitra

[17] Ibid

[18] Ibid

[19] Ibid

[20] Majumdar Shanker Ranjan: KALA- A journal of Indian art history congress/vol:xiii20072008;page 97-100

[21] https://en.wikipedia.org/wiki/pattachitra

[22] Ibid

[23] Mookerjee Ajit: Ibid page

[24] https://en.wikipedia.org/wiki/Kalamkari

[25] htpps://www.utsavpedia.com/motifs-embroideries/kalamkari-art

[26] https://en.wikipedia.org/wiki/Kalamkari

[27] https://www.utsavpedia.com/motifs-embroideries/kalamkari-art

[28] The designcart.com/blog

[29] https://en.wikipedia.org/wiki/Kalamkari

[30] Ibid-Kalamkari

[31] www.cyberkerala.com/ kalamezhuthu/index.html

[32] www.keralaculture.org/ kalamezhuthupattu/66-Ritualart forms of Kerala

[33] Ibid

[34] Keralatourism.org

[35] www.cyberkerala.com/kalamezhuthu/index.html

[36] https://www.gounesco.com>kalamezhuthu

[37] https://en.wikipedia.org/wiki/Warli_painting

[38] www.warli.in/2010/12/test-upload.html/warli

[39] https://en.wikipedia.org/wiki/Warli_painting

[40] Subramanian K.G. Moving Focus; Lalit Kala Academy New Delhi 1978 page 89

[41] Chatterjee Suniti Kumar Atreya, Bhikhan Lal Danielou Alian; Indian culture Universal Publication company Delhi - 61966 page 1

[42] Pandey Anjali: Indian folk art, Essence of Environmental Studies and Global peace, Shodh Samvat xxi-3/91

[43] Pandey Anjali: Traditional Toys Research Journal of Social and Life Sciences December 2014.

[44] Fig: $1 \& 2$ courtesy -culture trip (Pattachitra) Ibid "fair use"

[45] Fig: 3 courtesy- utsavpedia.com Ibid "fair use"

[46] Fig 4 courtesy- https//www.kerelataxis.com/kalamezhuthu "fair use"

[47] Fig 5 courtesy- https://www.shutterstock.com/warli painting "fair use"

[48] Fig courtesy-artzolo.com/traditional/folk-art/Warli Art "fair use" 